\title{
Strategic Uncertainty And Environmental Scanning Behaviors Among CEOs In Ghana
}

\author{
Ahmed Agyapong, Kwame Nkrumah University of Science and Technology, Ghana \\ Kofi Amanor, Kwame Nkrumah University of Science and Technology, Ghana \\ Abdul Samed Muntaka, Kwame Nkrumah University of Science and Technology, Ghana
}

\begin{abstract}
Fifty-nine CEOs from sectors across the country were sampled concerning their views on perceived uncertainty in seven environmental sectors and how it affects scanning behavior across the sectors. It was observed that the sectors in the task environment produced more strategic uncertainty than did sectors in the general environment. The results also showed that environmental scanning correlated positively with strategic uncertainty but that the frequency at which the environment is scanned varied across firms and industries and was CEO-specific. Moreover, when sector uncertainty was high, scanning involved a greater use of personal and external sources.
\end{abstract}

Keywords: Environmental Scanning; Strategic Management Process; External Opportunities \& Threats

\section{INTRODUCTION}

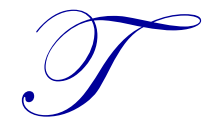

he effects of the environment on business demonstrate the need to monitor events in the domain in which business operations occur. Scanning is thus critical for the survival and progress of a business, as it allows an organization to pick up environmental signals cohesively, respond proactively to threats, and learn about possible glitches and opportunities. Some organizations have therefore adopted a structured and vigorous approach to scanning their environment for vital signals, while others rely on their CEOs' informal and ad hoc scanning behavior (Nystrom et al., 1996). The literature suggests that the complexity and volatility of the environment, coupled with the scarcity of its invaluable environmental resources, make scanning imperative. Daft and Weick (1984) describe scanning as the first stage in the strategic management process. It is taken for granted that the environment is a major source of uncertainty for managers who are responsible for identifying external opportunities and threats, implementing strategic changes, and achieving organizational/environmental alignment (Elenkov, 1997). How top managers perceive and interpret signals in their business domain therefore determines their strategic actions. As the uncertainty-scanning-performance relationship clearly bears significantly on strategic management, this line of inquiry has been of great interest to modern strategy scholars. Empirical investigations into the relationship among environmental scanning, business performance, and perceived uncertainty include Daft et al. (1988), Thomas et al. (1993), Elenkov (1997), May et al. (2000), Ebrahimi (2000), and Garg et al. (2003). However, no study has yet explored how CEOs in Africa perceive and respond to their environment.

Although Africa's environmental conditions are highly unpredictable and unstable, many resources exist to help businesses survive. Africa's environmental conditions require a proactive approach not only to domestic monitoring but also to keeping abreast with changing trends in the world economy, as domestic economies are very sensitive to shocks. The empirical works that have looked at the African setting include Sawyerr (1993), who conducts a comparative study on environmental scanning research in the Western context and relates it to the African context using CEOs' scanning behaviors in Nigeria. We will contribute to this growing research by concentrating on Ghanaian firms. Most research has concentrated on CEO behavior within a single industry, specifically the manufacturing sector, making it very difficult to generalize the conclusions - what might pertain to one industry may not in another, as every industry has its own peculiar structure, conditions, and needs and may align differently to the environment. We contribute to the literature by examining scanning behavior in various sectors of the economy and exploring whether perceived uncertainty differs across industries; if it does, industrial 
characteristics may play a role in general environmental scanning. We also inquire into how individual CEO characteristics impinge on the conduct of scanning in response to perceived strategic uncertainty. While previous works have focused on the direct relationship between environmental scanning and perceived uncertainty, this study looks not only at the direct linkage but at how it is affected by other characteristics relating to the firm, industry, and the CEO. We believe that, though these attributes may not be characteristically observed or compounded, their impact may be very significant. We find that strategic uncertainty positively correlates with environmental scanning but that the frequency at which the environment is scanned is stronger when such attributes as CEO and industrial characteristics are considered with other firm characteristics, such as firm size and business performance. The implication drawn is that firm size and improving performance increase strategic uncertainty, indicating the need for environmental scanning; how frequently the environment must be scanned across all media will vary across industries and CEOs, however. We also observe, based on the general contextual settings, that scanning patterns are all virtually the same, with personal and external sources used when sector uncertainty is high. However, scanning frequencies can differ.

\section{THEORETICAL FRAMEWORK}

The environment exerts a strong influence on the strategic action of an organization. Duncan (1972) defines the environment as all the physio-social peripheries of an organization that are considered in management decision making, both directly and indirectly. According to Bourgeois (1980), cited in Daft et al., (1988), the factors with a direct influence on an organization's operations constitute what is termed the task environment, ${ }^{l}$ while the factors that exercise an indirect control on transactions typically constitute what is called the general/remote environment. ${ }^{2}$ Asheghian and Ebrahimi (1990), cited in Sawyerr (1993), suggest that the constitution of these two main layers of the business environment is not monotonously static but, rather, depends on how the organization's boundaries are fixed and how its executives elect to explore those boundaries. Organizations function as open systems and hence need persistent interaction with their environments (Katz and Kahn, 1966; cited in Kemdirim, 1993).

What top managers' face outside their business domain poses a constant quandary. Perceived environmental uncertainty arises out of deficient information about the business environment, which, though habitually challenging and volatile, is where opportunities and valued resources are exploited for business growth. The dilemma is this: within the same risk set that threatens the organization there may be hidden unimaginable inherent advantages that the business organization can exploit if policymakers are able to place the puzzle pieces in the appropriate locations. Kemdirim (1993) suggests that organizations' adaptation to changing environments is driven by transformational leaders who appreciate the dynamic nature of the environment and institute the necessary strategic changes to their organizations in response to these volatile exterior conditions.

To do this, managers require a critical amount of access to relevant information in order to gauge their business returns against the risks and take informed strategic action based on the perceived environmental trends. The stark question for top managers is where to acquire this useful information. An uncertain environment strongly impacts the shape of an organization's structure and processes; hence, knowledge of the environment is critical to an organization's survival (Kemdirim, 1993). Decision-makers rarely lack information accessibility; the literature suggests that mangers have abundant environmental information (Hambrick, 1982). Galbraith (1977) defines environmental uncertainty as the relevant information gap between what has been obtained for work and what is actually needed for the work; it thus describes the degree of accuracy with which future environments can be predicted (Kemdirim, 1993).

To narrow this gap, managers are compelled to scan the environment and extract the information useful for decision making. Environmental scanning is thus the strategy an organization employs to cope with uncertainty and learn about relevant events and trends (Hambrick, 1981). It is the acquisition of information about events, trends, and relationships in an organization's environment, knowledge that will help decision makers identify and

\footnotetext{
${ }^{1}$ The task environment is composed of such sectors as competitors, customers, and factor suppliers (raw material suppliers, creditors, and trade unions).

${ }^{2}$ The general environment also comprises such sectors as technology and the socio-cultural, political/legal, and economic sectors (Sawyerr, 1993).
} 
understand strategic threats and opportunities (El Sawy, 1985); thus, its acceptance is a vital point of departure in the strategic management process (Aguilar, 1967; Daft and Weick, 1984). The process of scanning and selecting relevant information does not itself create uncertainty; rather, the complex nature of the environment, coupled with the rate at which environmental conditions change, produces perceived environmental uncertainty. Complexity is the extent to which useful events exterior to the organization are heteromorphic and copious while also carrying implications for business progress. The difficulties begin when this complex environment is also extremely dynamic: if relevant events' rate of change is high, external activities shift rapidly, making it difficult for decision makers to stay on top of the issues (Daft et al., 1988). Pfeffer and Salancik (1978) theorize that, when changes in relevant environmental events go unnoticed, decision makers fail to undertake the strategic adjustments they need to stay competitive, resulting in systematic errors made by top managers suffering a mismatch between their decision structure and environmental conditions. The result is a decline in business performance or, worse, a management crisis (see Andrew, 1971; Bourgeois, 1985; Thomas et al., 1993, Subramanian et al., 1993)

Top executives need to scan their environment and obtain information for strategic decisions, but their scanning behavior is not a direct response to perceived environmental uncertainty. What motivates scanning behavior is external events' importance to business performance; unimportant information would hold little value or interest to managers. The extent to which a sector provides materials for the attainment of organizational goals determines its importance to the business. Indeed, information from important sectors can even provide strategic advantage to a firm (Pfeffer and Salancik, 1978; Dutton and Freeman, 1984; Daft, 1986). For instance, in a highly important sector, external events are perceived to be directly linked to operations and performance. This implies that an organization that has a structured mechanism for obtaining constant information from such sectors or simply possesses information about the sector that the competition lacks, enjoys a virtual competitive edge over its compatriots. Hence, the combination of perceived uncertainty and sectorial importance delivers what is called in the literature strategic uncertainty. Strategic uncertainty signifies the absence of information about events and activities within environmental sectors where any occurrence can significantly impact the goals and operations of the business. Strategic uncertainty thus generates the need to conduct environmental scanning (Daft et al., 1988); perceived uncertainty alone does not ignite any special drive to fish for environmental facts. In principle, strategic uncertainty reflects the strategic value of environmental information to organizational performance (Elenkov, 1997).

\section{HYPOTHESES}

\section{Environmental Sectors and Strategic Uncertainty}

One of the empirical questions pursued by the environmental scanning research is which sectors of the environment generate greater strategic uncertainty. The literature suggests that the sectors of the direct (task) environment, given its immediate control of business operations, have more intricate systems and thus a higher rate of change than do those in the remote (general) environment. Hence, the task environment creates greater perceived strategic uncertainty than does the general environment (Daft et al., 1988; Pearce and Robinson, 1991; Thompson and Strickland, 1992). An investigation of this phenomenon within various contexts has proved the contrary, however: there is no significant difference between the perceived strategic uncertainties of the two main environmental layers (see Daft et al., 1988; Sawyerr, 1993; Elenkov, 1997; May et al., 2000). These empirical findings also reveal that the perceived strategic uncertainty of all environmental sectors is highly irregular, with mixed compositions in both the task and general sectors. Specifically, every contextual setting reflects a totally different sectoral ranking of highly strategic uncertainty, though the consumer sector is symptomatically seen as one of the most strategically uncertain sectors in all empirical studies. Most of these scanning studies have focused on the manufacturing sector, however, and generalizing them is thus problematic. We wish to maintain the earlier supposition that the task has greater strategic uncertainty than does the general or remote environment, but we will test this result across various industrial sectors, including the service, manufacturing, financial, construction, and ICT sectors.

The reason for our stance is that Ghana's market conditions are highly skewed towards the consumption of foreign products and services, forcing its businesses to constantly struggle to keep up with the changing tastes of its clients while producing competitive products that can do well in a highly liberalized and open market. 
Additionally, what pertains to the resource sector has been seen to affect most domestic businesses. Repeated industrial strikes, an inadequate supply of raw materials, and a chronic energy crisis have influenced most businesses across the country. The energy crises between 1997 and 1998 and 2006 and 2007, coupled with an always-unstable power supply, have had devastating effects on the economy and on businesses, particularly in energy-sensitive sectors like mining and manufacturing. Anecdotal evidence suggests that lack of access to power and interruptions in the power supply have caused production bottlenecks for cement manufacturing, at least in the last quarter of 2006, resulting in increased retail prices (CEPA, 2007). An inadequate supply of raw materials has also hurt Ghanaian businesses. For instance, after its establishment in the 1970s, the textile sub-sector dominated the manufacturing sector, accounting for almost $27 \%$ of manufacturing labor employment and $60 \%$ of plant capacity (MOTI, 2004, cited in Quartey, 2006); by 1982, however, a shortage of foreign exchange with which to import raw materials forced the sub-sector to operate far below capacity. Consequently, most of the industries went out of business, and the situation deteriorated during the trade reforms of the structural adjustment program (Quartey, 2006). The raw materials situation is severe for organizations relying on either local materials or foreign imports for production. Businesses have been hurt by the import of cheap substitutes from Western and East Asian countries and urban consumers' preference for these cheap imports, against which the textile and poultry sub-sectors find it next to impossible to compete. These factors have caused business closures and underperformance across the country. We therefore expect that issues concerning the consumer/market, factor suppliers, and competitors will create more uncertainty for CEOs in Ghana than issues concerning the economic or political sectors, important though they may be.

Hypothesis 1: Sectors in the task environment create greater perceived strategic uncertainty for top executives than sectors in the general environment.

\section{Scanning Behavior and Strategic Uncertainty}

Much of the scanning literature has investigated the impact of environmental factors on scanning behavior (see Daft et al., 1988; May et al., 2000; Elenkov, 2000; Ebrahimi, 2000). Significantly, these studies find that the frequency with which CEOs scanned the environment increased with the perceived uncertainty ("scanning frequency" here refers to the number of times policy makers receive information about sectors in the environment). Thus, the more important top managers perceive the sector to be (i.e., as something that provides useful information for decision making), the more managers will be inclined to scan the sector for information.

The current empirical interest in environmental scanning flows from the assumption that it results in growth and business performance (see Thomas et al., 1993; Garg et al., 2003). Newgren et al. (1984) find that scanningoriented firms perform significantly better than non-practicing firms, which Daft et al. (1988) explain through two logical scenarios. First, the positive relationship between performance and scanning could suggest that broader scanning provides a broader environmental perspective, thus increasing predictive accuracy and leading to the correct strategic action. Second, the higher firms move on the performance scale, the wider their scanning patterns become. Specifically, high performance firms may have optimized the use of their immediate environment and thus perceive new territories and markets into which to expand; low performing firms, however, concentrate their activities in small domains to first establish their niche in order to thrive in the market. This implies that, as firms grow, uncertainty also grows, requiring frequent and broad scanning. Indeed, the literature suggests a possible linkage between broader scanning and performance (see Dollinger, 1984): a cyclical relationship may exist among performance, size, uncertainty, and scanning. Intuitively, we also detect the possible impact on scanning patterns of industrial and CEO characteristics. We suggest that every industry has a unique set of risks and peculiar needs that may require particular scanning modes; moreover, the CEO's peculiar attributes impinge on the environmental scanning pattern he will be inclined to use. In fact, Kemdirim (1993) suggests that a business' responsiveness to changing trends depends on whether the CEO appreciates the dynamic nature of the environment; if he does, the manager will ensure that the necessary strategic changes are instituted within the organization in response to volatile exterior conditions. Hence, policymakers' awareness of the strategic value of environmental information for organizational performance and operations is critical. We ask whether scanning patterns in response to strategic uncertainty differ across industries or CEOs and, if they do, how this affects the linkage between scanning frequency and perceived strategic uncertainty. We postulate that perceived uncertainty does have an influence on 
environmental scanning but that this influence is strengthened by factors relating to the person doing the scanning, such as the firm characteristics, the nature of the business, and the attributes of the CEO.

Hypothesis 2: $\quad$ Perceived strategic uncertainty will correlate positively to scanning frequency.

Hypothesis 2b: Characteristics such as firm, industrial, and CEO characteristics do not affect scanning patterns but rather enhance scanning frequency.

Perhaps the most critical issue is the nature and form of data most relevant to CEOs' environmental assessment. Daft and Weick (1984) suggest that the source of information (scanning mode) is dependent on the organization's mode of interpretation; scanning information is obtained from both internal and external and from personal and written sources. The literature has largely confirmed the preponderance of personal sources, including face-to-face contact and telephonic media, over written sources (e.g., documents, income statements, reports, memos, newspapers) in environmental analyses. Written sources are beneficial, however, in the amount of information they carry. For instance, Tyler et al.(1989) indicate that highly (personal) and poorly (written) information-rich sources are both used less frequently under highly changing and unpredictable environmental conditions than under stable, predictable conditions and that poorly information-rich sources are used more frequently than highly rich sources under stable, predictable conditions. Others, like Daft and Lengel (1984), argue that personal sources are richer because they provide feedback and hence generate understanding when uncertainty is high. Personal information is therefore content-rich and allows top managers to interpret weak signals (Ansoff, 1975 cited in Daft et al., 1988). When perceived uncertainty increases, business executives are expected to search for or rely upon information from external sources in their decision making.

Hypothesis 3: There is a strong association between perceived strategic uncertainty and scanning from personal sources rather than written sources

Hypothesis 3b: External sources of assessment are more useful for CEOs when perceived uncertainty increases than are internal sources.

\section{METHODOLOGY}

\section{Sample Selection and Data Collection Processes}

A total of 59 CEOs from various industries were selected for the study in a process principally based on criteria used by Daft et al. (1988) and Sawyerr (1993). Sampling selection followed three criteria: the firm had to have a well-defined task environment, be autonomous - its strategic decisions based on environmental condition and not the policies of mother institutions, and have the structural and behavioral characteristics of a well-established entity with a firm size of no fewer than 20 employees. The second criterion forced the selection of only indigenous companies; to include institutions with some foreign investment, an annex was constructed in line with Sawyerr (1993), such that companies with at least 60\% Ghanaian equity interest qualified for selection.

All the firms fitting these criteria were selected from Accra and Kumasi, where most of Ghana's established organizations are situated. Data were collected through personal interviews with the CEOs of the selected organizations. The questionnaires were vigorously tested and revised through a series of interviews with business executives and fresh students pursuing the Commonwealth Executive MBA program at the Kwame Nkrumah University of Science and Technology, Ghana.

The final questionnaire comprised vivid explanations of the environmental sectors and concise questions on scanning behavior and patterns, from which responses were generated. It was observed during the pilot testing that the survey's five-point Likert scale ${ }^{3}$ was an effective way to measure the responses about the perceived rates of change, importance, and complexity, confirming the reliability of the instrumentation used by Daft et al. (1988) and Sawyerr (1993), which was also used by May et al. (2000).

\footnotetext{
${ }^{3} 1=$ low and $5=$ high

(C) 2012 The Clute Institute http://www.cluteinstitute.com/
} 


\section{Variable Measurement}

The variables of interest were all measured using the calculations provided by Daft et al. (1988), since this format has featured in a number of environmental scanning surveys (see Sawyerr, 1993; Choo, 1993; Elenkov, 1997; May et al., 2000).

Perceived strategic uncertainty (PSU) was measured as the product of the strategic importance and combined effect of strategic variability (rate of change) and complexity. Thus,

$\mathrm{PSU}=$ importance $*($ strategic variability + complexity $)$

After the perceived uncertainties were computed, PSU scores for both the task and general environments were averaged to obtain composite PSU scores for them.

These average scores were then assessed against the responses on scanning behavior to ascertain the empirical linkages. The variables of interest with respect to scanning behavior were scanning frequency and scanning mode. Scanning frequency, which measures the number of times CEOs retrieve information from sectors, was computed, ${ }^{4}$ while the scanning mode was estimated using a five-point Likert scale ${ }^{5}$ (see Daft et al., 1988; May et al., 2000).

Other variables of prime interest include the nature of the business (industrial characteristics), CEO characteristics, organizational size, and performance. The number of employees was used as a proxy for firm size, and performance was proxied by return on assets (ROA). Following Daft et al., (1988), ROA was averaged over three years (from 2009 to 2011) to reduce data aberration. The CEO characteristics factor was proxied by educational level. These variables assist an investigation and understanding of the linkage between scanning behavior and strategic uncertainty much more than control variables.

\section{Data Analysis and Results}

The means and standard deviation for each uncertainty and scanning variable were first calculated for each environmental sector; Scheffe's multiple range test was then used to conduct a multiple comparison of the estimated group of means and thus determine the statistically significant differences in strategic uncertainty across sectors. Pearson's correlation statistics between the major dependent and independent variables were then computed. Two estimation procedures were used: the first related scanning behavior and strategic uncertainty with no control variable, and the second established four different categories and estimated the linkages between the two variables and four control variables (organizational size, performance, CEO characteristics, and industrial characteristics) to discover the linkage between scanning behavior and perceived uncertainty and determine whether the empirical linkages are also influenced by other external factors.

A summary of the sector characteristics and scanning modes appears in Table 1. A Likert five-point scale was used to calculate the mean scores. The results show that the sectors in the task environment are more important, complex, and volatile than are the sectors in the general environment. Ranked among the highest strategic variable sectors are the customer, factor supplies, and competitor sectors, followed closely by the economic and technological sectors. Moreover, the perceived importance, variability, and complexity of the sectors in the task environment occasioned the concentration of scanning activities in these areas more than was the case in the general environment. Apart from the economic sector, the third most frequently scanned areas for written sources, the task environment was the most frequently scanned in all scanning modes. The economic sector was scanned more rapidly than was the competitor sector for written sources. Scanning on the economic sector was done through external sources more often than by internal sources. CEOs scan the competitor sector less frequently than the economic sector through written modes but more frequently through personal modes because (we believe) most of the information on the economic sector is received in the form of published reports (Daft et al., 1988). Moreover,

\footnotetext{
${ }_{5}^{4}$ See Daft et al. (1988).

5 The scanning mode was based on external, internal, personal, and written sources, using the Likert scale $(1=$ low and $5=$ high $)$. 
companies obtain most of their information about other companies' strategic activities through personal contacts or informants since it is very difficult, if not impossible, to obtain information about other competitors' blueprints through written documents. Companies find clues about what their competitors are doing only through advertisements, public displays, and symposia. Third, personal contacts are most prevalent in the competitors sector because most CEOs take advantage of clubs, associations, and other industrial peer review meetings to share ideas.

Table 1: Means and Rankings of Environmental Characteristics and Scanning Behavior

\begin{tabular}{|c|c|c|c|c|c|c|c|c|c|c|c|c|c|c|}
\hline \multicolumn{7}{|c|}{ SECTOR Characteristics ${ }^{\mathrm{a}}$} & \multicolumn{8}{|c|}{ SCANNING Mode ${ }^{b}$} \\
\hline & \multicolumn{2}{|c|}{ Importance } & \multicolumn{2}{|c|}{ Change } & \multicolumn{2}{|c|}{ Complexity } & \multicolumn{2}{|c|}{$\begin{array}{c}\text { Written } \\
\text { External }\end{array}$} & \multicolumn{2}{|c|}{$\begin{array}{l}\text { Written } \\
\text { Internal }\end{array}$} & \multicolumn{2}{|c|}{$\begin{array}{l}\text { Personal } \\
\text { External }\end{array}$} & \multicolumn{2}{|c|}{$\begin{array}{c}\text { Personal } \\
\text { Internal }\end{array}$} \\
\hline & MN & SD & MN & SD & MN & SD & MN & SD & MN & SD & MN & SD & MN & SD \\
\hline Task Environment & & & & & & & & & & & & & & \\
\hline Customer & 4.54 & .988 & 4.08 & 1.04 & 4.10 & 1.17 & 1.83 & 1.17 & 1.98 & 1.30 & 1.34 & 0.66 & 1.60 & 1.01 \\
\hline Factor Suppliers & 4.19 & 1.09 & 3.93 & 1.02 & 3.74 & 1.21 & 2.42 & 1.33 & 2.58 & 1.26 & 2.15 & 1.20 & 2.42 & 1.28 \\
\hline Competitor & 4.10 & 1.10 & 3.89 & 1.06 & 2.79 & 1.06 & 2.51 & 1.36 & 3.32 & 1.18 & 2.17 & 1.16 & 2.33 & 1.39 \\
\hline $\begin{array}{l}\text { General } \\
\text { Environment }\end{array}$ & & & & & & & & & & & & & & \\
\hline Economic & 3.98 & 0.96 & 3.86 & 0.99 & 4.03 & 1.03 & 2.49 & 1.18 & 2.63 & 1.17 & 2.37 & 1.11 & 2.51 & 1.14 \\
\hline Technology & 3.95 & 1.27 & 3.54 & 1.32 & 3.85 & 1.19 & 2.67 & 1.19 & 2.95 & 1.25 & 2.46 & 1.30 & 2.81 & 1.29 \\
\hline Political & 2.98 & 1.27 & 2.63 & 1.2 & 3.12 & 1.16 & 3.03 & 1.43 & 3.32 & 1.31 & 3.05 & 1.29 & 3.12 & 1.22 \\
\hline Sociocultural & 2.79 & 1.21 & 2.6 & 1.44 & 3.86 & 1.14 & 3.31 & 1.07 & 3.32 & 1.18 & 3.23 & 1.06 & 3.71 & 4.04 \\
\hline
\end{tabular}

a. $1=$ low, $5=$ high

b. $5=$ low, $1=$ high

Further examination was carried out to test the study's hypotheses. The analysis of PSU scores revealed that the average PSU score for the task environment was significantly higher than that for the general sector $(t=$ 7.685; $P=0.000$ ). This result confirms hypothesis 1 , that the task environment generates much more strategic uncertainty than does the general environment. A further probe showed that when the environmental sectors were segregated into task and general sectors, the three sectors generating the most strategic uncertainty were all from the task environment. The Scheffe's multiple range test, at a 5\% significance level, further revealed that each sector presented a different level of strategic uncertainty to policymakers. Starting from the highest to the lowest, the sector strategic uncertainties were classified as customer, factor suppliers, competitor, economic, technological, political, and socio-cultural.

Table 2 shows that each environmental sector involves a statistically different level of strategic uncertainty for CEOs in Ghana. The question is how this perceived uncertainty affects scanning patterns and whether this impact is spawned or enhanced by other firms, industrial, and CEO characteristics. The answers required the testing of hypotheses 2 and 3, which posit a positive relationship between perceived strategic uncertainty and scanning frequency and a stronger correlation between strategic uncertainty and scanning for personal sources than for written sources.

Table 2: Rankings of Environmental Sectors with Strategic Uncertainty

\begin{tabular}{|l|c|c|c|c|c|c|c|c|}
\hline \multicolumn{1}{|c|}{ Sectors } & Strategic Uncertainty & A. & B. & C. & D. & E. & F. & G. \\
\hline A. Customer & 3.8 & & $*$ & $*$ & $*$ & $*$ & $*$ & $*$ \\
\hline B. Factor suppliers & 3.4 & & & $*$ & $*$ & $*$ & $*$ & $*$ \\
\hline C. Competitor & 3.3 & & & & $*$ & $*$ & $*$ & $*$ \\
\hline D. Economic & 3.2 & & & & & $*$ & $*$ & $*$ \\
\hline E. Technology & 3.1 & & & & & & $*$ & $*$ \\
\hline F. Political/legal & 1.8 & & & & & & $*$ \\
\hline G. Socio-cultural & 1.5 & & & & & & & \\
\hline
\end{tabular}

Note: asterisks denote significant differences between sectors at a 5\% significance level based on Scheffe's multiple range tests.

Scores were also generated following Daft et al., 1988.

To test these hypotheses, we first estimated the correlation coefficient between scanning frequency and perceived uncertainty without any control variable to see the direct correlation between perceived uncertainty and 
scanning patterns. We then imputed other control variables in a stepwise manner to gauge the effects of the external variables on the empirical linkage between perceived uncertainty and scanning frequency. The outcome was the specification of five different models in the formulation of the empirical relationship between strategic uncertainty and scanning frequency, as displayed in Table 3.

Table 3: Empirical Relationship between Perceived Uncertainty and Scanning Frequency

\begin{tabular}{|l|c|c|c|c|c|}
\hline \multicolumn{1}{|c|}{ Scanning Freq } & PSU_0 & PSU_1 & PSU_2 & PSU_3 & PSU_4 \\
\hline All modes & 0.253 & 0.276 & 0.284 & $0.365^{*}$ & $0.482^{* *}$ \\
\hline All personal & $0.402^{* *}$ & $0.437^{* *}$ & $0.438^{* *}$ & $0.445^{* *}$ & $0.585^{* * *}$ \\
\hline All written & 0.136 & 0.139 & 0.140 & 0.168 & 0.245 \\
\hline All external & $0.364^{*}$ & $0.369^{*}$ & $0.370^{*}$ & $0.389^{*}$ & $0.416^{* *+}$ \\
\hline All internal & 0.264 & 0.285 & 0.295 & 0.297 & $0.335^{*}$ \\
\hline
\end{tabular}

Note: PSU_0 = no control variable in the relationship between PSU and scanning frequency

PSU_1 = estimating the relationship with size as the control variable

PSU_2 = estimating the relationship with size and performance as control variables

PSU_3 = estimating the relationship with size, performance, and CEO characteristics as control variables.

PSU_4 = estimating the relationship with size, performance, CEO and industrial characteristics as the control variables

$* 10 \%$ significance level; ** 5\% significance level; *** $1 \%$ significance level

+ All external sources are significantly greater than all internal sources $(P<0.001)$

We tested the hypotheses by computing a correlation statistic between PSU and scanning frequency for all scanning modes. Table 3 indicates a positive relationship between scanning frequency and perceived uncertainty; however, not all the correlation coefficients are significant across the table. Without controlling for any external variable, when strategic uncertainty increases, top executives are inclined to use more personal sources than written ones and more external modes than internal ones. Scanning in all modes increases as strategic uncertainty increases but is not significant. This scenario is repeated even when we control for firm characteristics using size and performance as predictors. The patterns are the same, but the frequency has increased. Performance and size are estimated as having a strong and positive relationship with strategic uncertainty. Correlation coefficients of 0.416 $(P<0.001)$ and $0.432(P<0.001)$ were obtained between performance and uncertainty and size and uncertainty, respectively. Scanning frequency differs significantly across CEOs $(r=0.683, P=0.000)$ and the nature of the business $(r=0.478 ; P=0.000)$. The question that remains is how these statistical differences (regarding scanning across industries and CEOs) affect scanning frequency and patterns. Table 3 shows that, while scanning patterns remain unchanged from when we consider firm characteristics alone, the frequency with which scanning is done increases. For instance, scanning in all modes is significant when we consider the influence of industrial and CEO characteristics, confirming hypothesis $2 \mathrm{~b}$ (that firm, industrial, and CEO characteristics do not affect scanning patterns but rather enhance the frequency of environmental assessments). Thus, using multiple sources for environmental scanning is not contingent on how chief executives perceive the environment but on other attributes specific to the 1) firm, 2) the firm's industry, and 3) other characteristics associated to the CEOs (see PSU_4). Put differently, scanning patterns will remain virtually constant across a country's contexts and conditions; the key difference is the frequency with which the environment is scanned - a frequency that will vary from firm to firm, industry to industry, and CEO to CEO.

\section{DISCUSSION \& CONCLUSION}

Businesses do not operate in outer space, but even there they would still need to consider the conditions within which they conducted their business; the external environment is an important factor in their survival. Thus, this study examined how top executives scan their environment to make strategic decisions. Our assumption was that environmental monitoring by chief executives is conducted not only as a result of increased perceived uncertainty, but also of other benign attributes perhaps specific to the firm, the industry, and the CEO. These benign attributes may not be analytically classified or appear conspicuous, but their influence on the linkage between perceived environmental uncertainty and environmental scanning is considerable. A total of 59 CEOs from various industries participated in a survey designed to discover whether the two main environmental layers (task and general) differ in their generation of strategic uncertainty, to examine whether scanning frequency correlates strongly and positively with strategic uncertainty, and to explore the patterns and modes by which the scanning is done. 
Our analysis shows that strategic uncertainty differed significantly across sectors, with customers, factor suppliers, and competitor sectors ranking highest (in descending order), above the economic, technological, political, and socio-cultural sectors. Thus, the task environment generated more strategic uncertainty than did the general environment. Furthermore, the perceived increases in strategic uncertainty resulted in a frequent scanning of the environment in every scanning mode for useful information. However, chief executives used more personal sources than impersonal ones and more external modes than internal ones when perceived uncertainty was aggravated. The greater preference for personal modes under increased uncertainty reflects the inability to acquire hard data when events are fluid and unclear (Weick, 1985 cited in Daft et al., 1988). Written sources are used frequently in sectors where conditions are stable and predictable. Personal sources are richer and can provide feedback, generate understanding, and be used to interpret weak signals when uncertainty is high (Daft and Lengel, 1986).

Concerning the alterability of scanning patterns in response to strategic uncertainty, scanning patterns did not change, but scanning frequency increased when we controlled for attributes specific to the firm, the industry, and the CEO. Thus, personal and external sources are more critical in CEOs' environmental assessments than impersonal and internal modes. Strikingly, scanning in all modes through multiple sources under high uncertainty is frequent when these surrogate benign attributes are considered in the analysis, implying that scanning in multiple media is not contingent on perceived strategic uncertainty as such. Firm characteristics (organizational size and performance) do not alone guarantee this linkage; rather, the guarantee is provided by industry and CEO attributes.

Specifically, environmental scanning is positively related to perceived uncertainty, but the frequency with which the environment is scanned is not explained by uncertainty alone, but also by such factors as CEO characteristics, the nature of the business, and firm characteristics.

\section{AUTHOR INFORMATION}

Ahmed Agyapong is a Lecturer at the Department of Marketing and Corporate Strategy, Kwame Nkrumah University of Science and Technology, Ghana. He holds qualifications in MBA, MA, BA, Dip in Marketing and is currently pursuing a PHD in Corporate Strategies. His research interests are corporate strategies, family business strategies and strategies for SMEs. Ahmed has taught Marketing Management and Strategic Management and Policy at both Undergraduate and Masters levels for over five years. E-mail: deedat31@yahoo.co.uk (Corresponding author)

Kofi Amanor, Department of Economics, Kwame Nkrumah University of Science and Technology, KumasiAshanti, Ghana. E-mail: kofiamanor@yahoo.com

Abdul Samed Muntaka is a Lecturer at the Department of Information Systems and Decision Sciences, Kwame Nkrumah University of Science and Technology, Ghana. He holds a BA in Economics and Geography from the Kwame Nkrumah University of Science and Technology, an MSC degree in Urban Affairs from Hunter College, and an MPA in Public Administration from John Jay College of Criminal Justice, all of the City University of New York. Muntaka has taught courses in Business Economics, Supply Chain Management, and Transportation Management at the undergraduate level and Project Management at both the undergraduate and graduate levels for over four years. E-mail: abusamgh@yahoo.com

\section{REFERENCES}

1. Aguilar F. J. (1967), "Scanning the business environment" Macmillan, New York.

2. Andrew, K. R. (1971), "The Concept of Corporate Strategy” Down Jones-Irwin, Homewood, IL.

3. Ansoff, H.I. (1975), "Implanting Strategic Management”, 2nd ed., New York: Prentice Hall.

4. Asheghian, P. and Ebrahimi, B. (1990), "International Business". Harper and Row Publishers, NY

5. Bourgeois, L. J. (1985), "Strategy and Environment: A Conceptual Integration," Academy of Management Review, 5, pp. 25-39.

6. Choo, W. C. (1993), "Environmental Scanning as Information Seeking and Organizational Learning," Information Research, 7(1) 
7. CEPA (2007), "Selected Economic Issues: Current State of the Ghanaian Economy", No. 14

8. Choo, C. W. (1999), "The art of scanning the environment", American Society for Information

Science.Bulletin of the American Society for Information Science Washington Vol. 45, No. 3, pp. 21-24.

9. $\quad$ Daft, R. L., (1986), Organizational Theory and Design, West, St Paul, MN.

10. Daft, R. L. and K. E. Weick (1984), "Toward a model of organizations as interpretation systems," Academy of Management Review, 9, pp. 284-295.

11. Daft, R. L., J. Sormunen and D. Parks (1988), “Chief Managers', executive scanning, environmental characteristics, 193-and company performance: An empirical study," Strategic Management Journal, 9(2), pp. 123-139.

12. Daft, R. L., and Lengel, H. R. (1986), "Organizational Information Requirement, Media Richness and Structural Design,” Management Science, 32, pp. 554-571.

13. Dollinger, Marc J. (1984), "Environmental boundary spanning and information processing effects on organizational performance," Academy of Management Journal 27 (2), 351-368.

14. Duncan, R. B. (1972), "Characteristics of Organizational Environments and Perceived Environmental Uncertainty,” Administrative Science Quarterly, 17, pp. 313-327.

15. Dutton, J.M. and Freeman, R. D. (1984), “Uncertainty and Firms' Strategic Behaviors”, New York University.

16. Ebrahimi B. P., (2000), "Perceived Strategic Uncertainty and Environmental Scanning Behavior of Hong Kong Chinese Executives", Journal of Business Research, 49, 67-77

17. Elenkov, D. S. (1997), "Environmental Uncertainty and Environmental Scanning Activities in Bulgarian Companies: A Comparative Study," paper presented at the 1994 Academy of Management Meeting, Dallas, TX.

18. El Sawy O. A. (1985), "Personal information systems for strategic scanning in turbulent environments: can the CEO go on-line?" MIS Quarterly, Mars, 53-60

19. Garg, V, Walters, B., \&Priem, R. (2003), "Chief Executive Scanning Emphasis, Environmental Dynamism, and Manufacturing Firm Performance," Strategic Management Journal, 24, 725-744.

20. Hambrick, D. C. (1982), "Environment, Strategy, and Organizational Strategy," Strategic Management Journal, 3, pp. 159-174

21. Hambrick, D. C. (1981), "Environment, Strategy, and Power within Top Management Teams," Administrative Science Quarterly 26,253-276

22. Katz, D. and Kahn, R. L. (1966), "Social Psychology of Organisations", New York: Wiley

23. Kemdirim, G. (1993), "CEO Transformational Leadership and its Impact on Strategic Change when Moderated by Environmental Uncertainty", Thesis submitted to the Faculty of Commerce, Concordia University, Canada

24. May, R. C., Stewart, W. H. Jr., and Sweo, R. (2000), "Environmental Scanning Behavior in a Transitional Economy: Evidence from Russia," The Academy of Management Journal, 43(3). Pp. 403-427.

25. Newgren, Kenneth E., Rasher, Arthur A. \&LaRoe, Margaret E. (1984), “An empirical investigation of the relationship between environmental assessment and corporate performance" Paper read at Proceedings of the 44th Annual Meeting of the Academy of Management, August 12-15 1984, at Washington, DC.

26. Pfeffer, Jeffrey, \&Salancik, Gerald R. (1978), “The external control of organizations: a resource dependence perspective” New York, NY: Harper \& Row.

27. Sawyerr, O.O. (1993), "Environmental Uncertainty and Environmental Scanning Activities of Nigerian Manufacturing Executives: A Comparative Analysis," Strategic Management Journal, 14(4), pp. 287-299

28. Subramanian, R., Fernandes, N., and Harper, E., (1993), "Environmental scanning in US companies: their nature and their relationship to performance." Management International Review 33(3), 271-286

29. Thomas, J., Clark S., Gioia D. (1993), "Strategic Sensemaking and Organizational Performance: Linkages among Scanning, Interpretation, Action, and Outcomes," Academy of Management Journal, 36(2), 239270.

30. Quartey, P. (2006), "The textiles and clothing industry in Ghana," in H. Jauch and R. Traub-Merz (Eds.), The Future of the Textile and Clothing Industry in Sub-Saharan Africa, pp. 134-146, Friedrich-EbertStiftung, Bonn. 